Strahan. HCA Healthcare Journal of Medicine (2020) 1:6

https://doi.org/10.36518/2689-0216.1202

\title{
Poetry
}

\section{Still Learning: COVID Through the Eyes of a Medical Student}

Alexis Strahan, MSN-FNP, MS-2,"

\section{Abstract}

\section{Description}

As a first-year medical student when the COVID-19 pandemic found a foothold, I felt an overwhelming amount of emotions that accompanied the pandemic's spread. Fear, although a reasonable choice, was not the first emotion that I experienced. In fact, it was a general feeling of paralysis. I had not six months prior taken an oath to commit my career and life to the service of the public's health care needs, yet I could provide little more than the textbook knowledge of biochemistry or genetics from my first semester of learning. My hands felt unarmed and unskilled for the fight. What could I do to alleviate any of the suffering? This writing was my response to that question. I found myself watching and seeking to emulate the selfless bravery of the health care workers who I saw facing the battle head on. This is for all the frontline heroes who gave everything. The next generation was watching, and we hope we can honor you in our lives' work.

\section{Keywords}

COVID-19; SARS-CoV-2; coronavirus infections; pandemics; medical education; undergraduate medical education; humanities; poetry; hope

Our white coats were as fresh as the

Hippocratic Oath on our lips,

Our eyes buried in the lines of text and on figures of the human bodies we would one day treat.

Tunneled into our task at hand,

We were bustling, busy in our search for what it meant to be a physician.

We were still learning.

It found us in the midst of our busyness and in our searching,

Not in the lines of a book but in the headlines on our screens.

It found us in the stillness and in the quiet of an outside world set on pause.

A contrast to the roar of those we watched in battle inside hospital walls.

We were still learning.

Both daylight and midnights met tired, prepared hands inside those walls.

Hands held through plastic as life began and life ended,
Other minds tested and sharpened on lab benchtops in the name of saving even more.

We saw it in the lives of the white coats' and blue scrubs' unwavering answer to the call.

We were still learning.

Like the crafted rhythms of the human body, illness lies quiet until history repeats again.

Then it will be our turn,

But we have seen the answer to our searching in the bravery of those who have gone before us.

We know now what it means to be a physician. Continually learning.

\section{Conflicts of Interest}

The author declare she has no conflicts of interest.

\section{Author Affiliation}

1. Mercer University School of Medicine, Savannah, GA

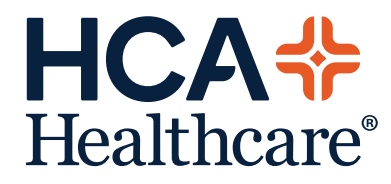

www.hcahealthcarejournal.com

(c) 2020 HCA Physician Services, Inc. d/b/a Emerald Medical Education
HCA Healthcare Journal of Medicine 